\title{
BURSITE COTOVELAR AGUDA EM FILHOTE: RELATO DE CASO
}

\author{
Fernanda Vieira Henrique ${ }^{1^{*}}$ \\ Carla Lauise Rodrigues Menezes Pimenta ${ }^{2}$ \\ Rosileide dos Santos Carneiro ${ }^{3}$ \\ Angélica Ramalho de Araújo Leite ${ }^{4}$ \\ Rafaela Alves Dias
}

HENRIQUE, F. V.; PIMENTA, C. L. R. M.; CARNEIRO, R. dos S.; LEITE, A. R. de A.; DIAS, R. A. Bursite cotovelar aguda em filhote: relato de caso. Arq. Ciênc. Vet. Zool. UNIPAR, Umuarama, v. 17, n. 3, p. 185-187, jul./set. 2014.

RESUMO: Bursite cotovelar é uma cavidade preenchida por fluido, circundada por tecido conjuntivo fibroso denso, que surge na face lateral do olécrano. Normalmente, essa condição clínica é causada por traumatismo crônico. Relata-se um caso de bursite cotovelar aguda bilateral em um cão da raça dálmata, macho, de 35 dias de idade. Clinicamente, o animal apresentava aumento de volume flutuante e indolor, na região do olécrano, bilateral, de um dia de evolução. Na punção aspirativa foi observado um líquido de aspecto seroso e vermelho, e no exame citológico apenas leucócitos e hemácias. Devido ao histórico e tempo de evolução, o diagnóstico presuntivo foi de bursite cotovelar traumática aguda. O tratamento preconizado foi à base de anti-inflamatório, tratamento tópico, bandagem ao redor da lesão e repouso. O cão retornou com sete dias totalmente recuperado. Apesar da bursite em pequenos animais ocorrer devido a traumas repetidos, apresentando uma característica de cronicidade, a bursite pode ser aguda e se originar de um único trauma.

PALAVRAS-CHAVE: Cão. Higroma. Olécrano. Trauma.

\section{ELBOW ACUTE BURSITIS IN A PUPPY: CASE REPORT}

\begin{abstract}
Elbow bursitis is a cavity filled with fluid and surrounded by dense fibrous connective tissue, which appears on the lateral side of the olecranon. Typically, this medical condition is caused by chronic trauma. This paper reports a case of bilateral acute bursitis in the elbow in a Dalmatian dog, male, with 35 days of age. Clinically, the animal presented painless swelling of the floating volume in the olecranon region, bilateral, with a one-day evolution. In aspiration, serous red fluid could be observed, and upon cytological examination, only leukocytes and erythrocytes were observed. Due to the history and evolution time, the presumptive diagnosis was that of acute traumatic bursitis in the elbow. The treatment was based on anti-inflammatory medication, topical treatment, bandage around the lesion and rest. The dog returned after 7 days fully recovered. Although bursitis occurs in small animals due to repeated trauma, presenting a chronicity characteristic, it can also be acute and originated from a single trauma.
\end{abstract}

KEY WORDS: Dog. Hygroma. Olecranon. Trauma.

\section{BURSITIS AGUDA DE CODO EN CACHORRO DE PERRO: RELATO DE CASO}

RESUMEN: La bursitis de codo es una cavidad llena de fluido y rodeada por tejido conectivo fibroso denso, que surge en el lado lateral del olécranon. Por lo general, esa condición clínica es causada por un trauma crónico. Se presenta un caso de bursitis aguda bilateral en el codo de un perro de la raza dálmata, macho, de 35 días de edad. Clínicamente, el animal presentaba aumento de volumen flotante y sin dolor, en la región del olécranon, bilateral, un día de evolución. En una aspiración se ha observado un líquido de aspecto seroso y rojo, y en el examen citológico sólo leucocitos y eritrocitos. Debido al histórico y tiempo de evolución, el diagnóstico presuntivo fue bursitis de codo traumática aguda. El tratamiento preconizado fue a base de antiinflamatorio, tratamiento tópico, vendaje alrededor de la lesión y reposo. El perro volvió con siete días totalmente recuperado. Aunque la bursitis se produce en animales pequeños debido a traumas repetidos, presentando una característica de cronicidad, la bursitis puede ser aguda y originarse a partir de un único trauma.

PALABRAS CLAVE: Perro. Higroma. Olécranon. Trauma.

\section{Introdução}

Bursite cotovelar, também denominada olecraniana, ou higroma ou seroma cotovelar, é uma cavidade preenchida por fluido, circundada por tecido conjuntivo fibroso denso, que surge na face lateral do olécrano (FOSSUM, 2013).

Segundo Buono et al. (2012) a forma pós-traumática da bursite cotovelar em humanos é a mais frequente e ocorre

DOI: https://doi.org/10.25110/arqvet.v17i3.2014.4943

${ }^{1}$ Médica Veterinária, Mestre em Medicina Veterinária, Doutoranda do Programa de Pós-Graduação em Medicina Veterinária da Universidade Federal de Campina Grande, Campus de Patos, Paraíba. Email: nandinhavh@gmail.com. Rua Dr. José Genuíno, 361, apt. 303, Centro, Patos, Paraíba.

${ }^{2}$ Médica Veterinária, Mestre em Medicina Veterinária, Doutoranda do Programa de Pós-Graduação em Medicina Veterinária da Universidade Federal de Campina Grande, Campus de Patos, Paraíba. Email: carlalauise@hotmail.com. Rua Jeová Bezerra, nº 110, apto 102, centro, Cep: 58700-090 Patos, Paraíba, Brasil

${ }^{3}$ Médica Veterinária, Mestre em Medicina Veterinária. Email: rosileide_carneiro@yahoo.com. Rua: Rua 5 de agosto, 173, apto 201, bl A, Patos, Paraíba.

${ }^{4}$ Médica Veterinária, Mestre em Medicina Veterinária. Email: angelica_ral@yahoo.com.br. Rua: Tarcísio Galvão, 2090, apto 11, Nova Descoberta, Natal, Rio Grande do Norte.

${ }^{5}$ Médica Veterinária, Mestre em Medicina Veterinária. Email: rafa.ad@hotmail.com. Rua Felix Carolino Barbosa, n 395, térreo, Bairro Alto Branco, Cep 58401-485, Campina Grande/PB. 
consequente à hemorragia dentro da bolsa sinovial e liberação de mediadores inflamatórios. Em animais, normalmente, essa condição clínica é causada por traumatismo crônico e ocorre bilateralmente como um edema indolor (FOSSUM, 2013).

Cães jovens, entre seis e 18 meses de idade, bem como raças grandes, são mais predispostos. Além disso, cães magros também apresentam uma maior predisposição, uma vez que apresentam uma gordura subcutânea mais delgada (SIQUEIRA FILHO et al., 2009).

As bursites cotovelares variam em tamanho, podendo ficar maiores à medida que o animal sofre traumatismos repetidos. Inicialmente, são estéreis, podendo se tornar infectadas durante uma aspiração para realização de citologia (FOSSUM, 2013).

Clinicamente, os diagnósticos diferenciais incluem cistos, neoplasias císticas e granulomas fúngicos ou bacterianos (MEDLEAU; HNILICA, 2003). Radiografias em casos de bursites de origem traumática podem excluir a possibilidade de fratura do olécrano (BUONO et al., 2012). O prognóstico é reservado, no entanto, lesões recentes respondem bem ao tratamento com bandagens, enquanto lesões antigas podem necessitar de drenagem ou extirpação (SCOTT; MILLER; GRIFFIN et al., 2001).

Objetivou-se com esse relato, descrever um caso de bursite cotovelar aguda em um canino jovem.

\section{Relato do caso}

Um canino, Dálmata, macho, com 35 dias de idade, foi atendido no Hospital Veterinário do Centro de Saúde e Tecnologia Rural (CSTR) da Universidade Federal de Campina Grande (UFCG) Campus de Patos/PB, no presente ano, apresentando um aumento de volume flutuante e indolor, na região do olécrano, bilateral (Figura 1), o qual, segundo o proprietário, havia surgido após o animal ter sido submetido a uma viajem de, aproximadamente, cinco horas no dia anterior. $\mathrm{O}$ animal havia sido deslocado, juntamente com mais quatro filhotes, no banco de trás de um carro, sem proteção nenhuma. Clinicamente o animal estava bem, com todos os parâmetros fisiológicos dentro do padrão de normalidade, e não apresentava claudicação e nem sensibilidade dolorosa na região do edema.

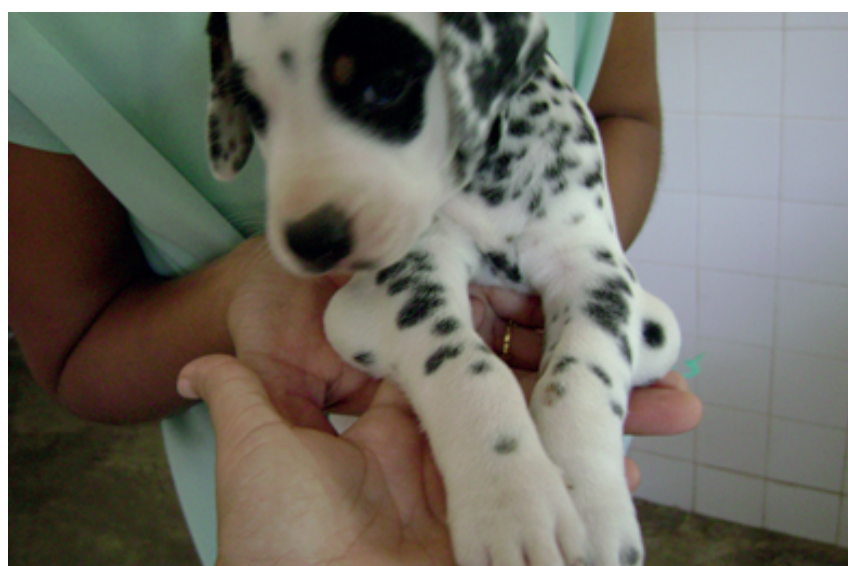

Figura 1: Cão da raça Dálmata com 35 dias de idade, apresentando um aumento de volume flutuante e indolor, na região do olécrano, bilateral. Fonte: Arquivo pessoal, 2014.
Realizou-se punção aspirativa por agulha fina para realização de exame citológico, em que foi observado um líquido de aspecto seroso e vermelho (Figura 2), e na microscopia foram observados apenas leucócitos e hemácias. $\mathrm{O}$ diagnóstico foi de bursite cotovelar traumática aguda.

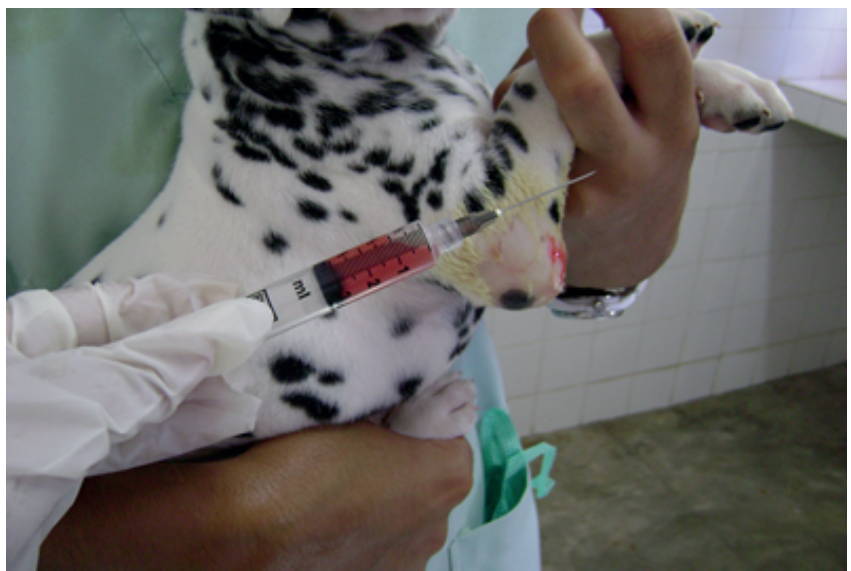

Figura 2: Punção aspirativa por agulha fina da região do olécrano para realização de exame citológico. Presença de líquido de aspecto seroso e vermelho em um cão jovem da raça Dálmata, 2014. Fonte: Arquivo pessoal, 2014.

$\mathrm{O}$ tratamento preconizado foi à base de anti-inflamatório (Cloridrato de Benzidamina ${ }^{6}, 1 \mathrm{mg} / \mathrm{kg}$, a cada 24 horas, por 5 dias), tratamento tópico (Dimetilsulfóxido gel ${ }^{7}$, a cada 12 horas, por 5 dias) e bandagem ao redor da lesão. Além disso, foi recomendado repouso. O cão retornou após sete dias totalmente recuperado.

\section{Discussão}

Este relato descreve um caso de bursite cotovelar aguda em um canino de 35 dias de idade. Segundo Siqueira Filho et al. (2009) esta condição clínica ocorre mais comumente em cães jovens com idade entre seis e 18 meses, o animal em questão era jovem, porém não se encaixava nessa faixa etária, provavelmente devido à origem traumática da bursite. A patogênese das bursites está relacionada principalmente com a idade dos indivíduos afetados, que por serem jovens ainda não desenvolveram calos de proteção (JOHNSTON, 1996).

Considerou-se o diagnóstico de bursite cotovelar devido à característica macroscópica da lesão e do líquido obtido durante a punção, concordando com Medleau e Hnilica (2003) que afirmam que as bursites são vistas como aumentos de volume semelhantes a cistos, moles a flutuantes e repletos de líquido vermelho. A classificação da bursite em aguda foi devido à origem desta, que, provavelmente, foi originada de um trauma que o animal deve ter sofrido durante a referida viagem. Vale salientar que, embora a bursite tenha se apresentado de forma edematosa e indolor, essas caraterísticas não permitem diferenciar um processo séptico de asséptico (BUONO et al., 2012), daí a importância da realização da citologia.

O tratamento do caso em questão foi eficaz devido à lesão ser aguda, já que Scott, Miller e Griffin (2001) afirmam

${ }^{6}$ Benflogin drágeas 50mg, Aché, São Paulo - SP.

${ }^{7}$ DM-GEL, Vetnil, Louveira - SP. 
que lesões recentes respondem bem ao tratamento, principalmente quando se utilizam bandagens. Além disso, o uso de anti-inflamatório e de tratamento tópico auxiliou a diminuir o processo inflamatório decorrente do trauma. O repouso recomendado nesse caso foi de extrema importância, uma vez que o tratamento primário de bursites cotovelares consiste na eliminação do traumatismo repetido (SIQUEIRA FILHO et al., 2009).

\section{Conclusão}

Este relato registra um caso de bursite cotovelar aguda em um filhote canino da raça Dálmata com 35 dias de idade, mostrando que a bursite pode ser aguda e se originar de um único trauma. $\mathrm{O}$ método de diagnóstico mais eficaz nestes casos é o exame citológico e o tratamento clínico tem potencial curativo quando a lesão é recente.

\section{Referências}

BUONO, A. D. et al. Diagnosis and management of olecranon bursitis. The Surgeon, v. 10, p. 297-300, 2012.

FOSSUM, T.W. Soft Tissue Surgery. In: Small Animal Surgery. 4. ed. St. Louis: Mosby, 2013. p. 268269.

JOHNSTON, D. E. Bursite e tendinite. In: BOJRAB, M.J. Mecanismos da moléstia na cirurgia dos pequenos animais. $2^{\circ}$ ed. São Paulo: Roca, 1996. p. 1252-1257.

MEDLEAU, L.; HNILICA, K. A. Dermatologia de pequenos animais - Atlas colorido e guia terapêutico. São Paulo: editora Roca, 2003. 353 p.

SCOTT, D. W.; MILLER, W. H.; GRIFFIN, C. E. Muller $\boldsymbol{\&}$ Kirk - Dermatologia dos pequenos animais. Philadelphia: Saunders Company. 1528 p.

SIQUEIRA FILHO, R. S. et al. Higroma cotovelar em canino: relato de caso. In: JORNADA DE PESQUISA, ENSINO E EXTENSÃO, 9., 2009, Recife, Pernambuco. Anais... Recife, 2009. CD-ROM.

Recebido em: 28/04/2014 Aceito em: 17/12/2014 